\title{
Users' reports and evaluations of out-of-hours health care and the UK national quality requirements: a cross sectional study
}

John Campbell, Martin Roland, Suzanne Richards, Andy Dickens, Michael Greco and Peter Bower

\author{
ABSTRACT \\ Background \\ National standards for delivery of out-of-hours services \\ have been refined. Health service users' preferences, \\ reports, and evaluations of care are of importance in a \\ service that aims to be responsive to their needs. \\ Aim \\ To investigate NHS service users' reports and \\ evaluations of out-of-hours care in the light of UK \\ national service quality requirements. \\ Design \\ Cross sectional survey. \\ Setting \\ Three areas (Devon, Cornwall, Sheffield) of England, UK \\ Method \\ Participants were 1249 recent users of UK out-of-hours \\ medical services. Main outcome measures were: users' \\ reports and evaluations of out-of-hours services in \\ respect of the time waiting for their telephone call to the \\ service to be answered; the length of time from the end \\ of the initial call to the start of definitive clinical \\ assessment ('call back time'); the time waiting for a \\ home visit; and the waiting time at a treatment centre. \\ Results \\ UK national quality requirements were reported as being \\ met by two-thirds of responders. Even when responders \\ reported that they had received the most rapid response \\ option for home visiting (waiting time of 'up to an hour'), \\ only one-third of users reported this as 'excellent'. \\ Adverse evaluations of care were consistently related to \\ delays encountered in receiving care and (for two out of \\ four measures) sex of patient. For $50 \%$ of users to \\ evaluate their care as 'excellent', this would require calls \\ to be answered within 30 seconds, call-back within \\ 20 minutes, time spent waiting for home visits of \\ significantly less than 1 hour, and treatment centre \\ waiting times of less than 20 minutes. \\ Conclusion \\ Users have high expectations of UK out-of-hours \\ healthcare services. Service provision that meets \\ nationally designated targets is currently judged as \\ being of 'good' quality by service users. Attaining \\ 'excellent' levels of service provision would prove \\ challenging, and potentially costly. Delivering services \\ that result in high levels of user satisfaction with care \\ needs to take account of users' expectations as well as \\ their experience of care.

\section{Keywords} \\ out-of-hours medical care; primary care; quality of \\ health care; questionnaire; satisfaction; standards; \\ unscheduled care.
}

\section{INTRODUCTION}

The NHS has defined criteria and standards of attainment for providers of out-of-hours services. These standards were developed following a national review of unscheduled care provision ${ }^{2}$ and defined after consultation with the Royal College of General Practitioners, while taking account of government policy. ${ }^{3}$ The development of the out-of-hours patient questionnaire, a valid and reliable survey instrument suitable for evaluating patients' experience of out-ofhours services within the UK, has recently been described. ${ }^{4}$

Patient's experiences of, and satisfaction with care are increasingly used to inform models of service delivery. ${ }^{5}$ From a theoretical perspective, it has been suggested that users' views of health services can be described as either preferences, evaluations, or reports of their experiences. ${ }^{6}$ Preferences assess patients' choices and desired outcomes regarding their health care, and, as such, can be assessed in samples of responders who may or may not have experienced the services under consideration. In contrast, both evaluations and reports are based on direct experiences of care.

J Campbell, professor; S Richards, senior lecturer; A Dickens, research fellow, Primary Care Research Group, Peninsula Medical School, Exeter. M Roland, director, P Bower, reader, National Primary Care Research and Development Centre, University of Manchester, Manchester. M Greco, CFEP UK Surveys, Exeter.

Address for correspondence

Professor John Campbell, Peninsula Medical School, General Practice and Primary Care, Smeall Building, Magdalen Road, Exeter, EX1 2LU. E-mail: john.campbell@pms.ac.uk

Submitted: 12 September 2008; Editor's response: 7 November 2008; final acceptance: 27 November 2008. (B) British Journal of General Practice.

This is the full-length article of an abridged version published in print. Cite this article as: Br J Gen Pract 2009; DOI: 10.3399/bjgp09X394815 
Evaluations seek patients' views on their experiences of healthcare services and of the adequacy of the care provided, while reports refer to observations regarding the organisation or process of care, which are divorced from statements regarding the adequacy of the care provided. In this study, users' reports of their experiences were examined and related to users' evaluations of the care they received, focusing on four nationally designated standards of out-of-hours care.

\section{METHOD}

As part of the development process of the out-ofhours patient questionnaire, three English out-ofhours service providers invited consecutive service users to complete a postal questionnaire about their experience of the service. ${ }^{4}$ Samples were drawn from three volunteer sites in south-west and northern England (Cornwall, Devon, Sheffield). These areas were identified as they work across a range of urban, rural, and inner-city patient populations with diverse community profiles in respect of geography, ethnicity, and demography. A different out-of-hours care provider organisation provided care at each of the three sites.

All three adopted models of care, which were similar, have been previously described in detail. ${ }^{4,7}$ The size of the sample was sufficient to support the process of questionnaire design. ${ }^{8}$ The study took into account best practice and guidance in the conduct of postal surveys of health users ${ }^{9,10}$ within resource constraints. Consequently, personalised letters to potential participants, in coloured ink, were sent by first class post with a stampedaddressed return envelope.

Following ethical approval in September 2005, sampling took place within 2 weeks of out-of-hours contacts. To minimise bias users requesting care at weekends and/or evenings were included in each area. Detailed methodology of the survey process, including the rationale for excluding around $30 \%$ of calls (for example, nursing-home residents and those with end-stage terminal illness) from the sampling frame, is described elsewhere. ${ }^{4}$ Contact details of a consecutive sample of 1249 recent calls to the out-ofhours service providers were extracted, and providers sent a numbered questionnaire, information sheet, and reply-paid envelope to the patient (or parent or guardian if the patient was a child). A reminder questionnaire was sent to non-responders after 2 weeks. Participants reported their experience of care in terms of making contact with out-of-hours services; the outcome of their contact; the consultation with the health professional; and their experience of home visiting or treatment centre attendance (if relevant). Within each domain,

\section{How this fits in}

The NHS has defined criteria and standards of attainment for providers of outof-hours services. Users' reports of their experiences of out-of-hours care were examined and related to their evaluations of the care they received. UK out-ofhours service users have exacting standards in respect of their care which may prove challenging for providers to meet.

responders were asked to report on their experience of care, and then (separately) to evaluate their experience using a 5-point scale.

Participant responses were examined in the light of four of the 13 nationally-designated requirements defined for service delivery by the NHS. ${ }^{1}$ The four standards (Box 1) related to the time taken in answering the telephone call to the service (standard

\section{Box 1. Four national quality requirements and associated report questionnaire items from the out-of-hours questionnaire. $^{a}$}

National quality requirements

- Standard 8: Initial call must be answered by a person within 60 seconds if there is an introductory message, and within 30 seconds if there is no message.

- Standard 9: A definitive clinical assessment (triage) for all calls must be begin within 60 minutes of the call, be answered by a person, and within 20 minutes for urgent calls.

- Standard 10: A definitive, face-to-face clinical assessment for all patients must begin within 60 minutes of the patient arriving at the treatment centre and within 20 minutes for patients with urgent needs. If no prioritisation system is in place, the assessment must begin within 20 minutes for all patients.

- Standard 12: A definitive, face-to-face clinical assessment at the patient's home must take place within 6 hours, and within 2 hours for patients with urgent needs, and 1 hour for patients with emergency needs.

Report items:

Please estimate how long it took for your call to be answered:

$<30$ seconds 30-60 seconds $>60$ seconds

How long did it take for a health professional to call you back? $\quad<20$ minutes 20-60 minutes $>1$ hour

How long did you have to wait for a health professional to visit you at home?

$<1$ hour

$1-2$ hours

$>2$ hours

How long did you have to wait (at the treatment centre) before having treatment?

$<20$ minutes 20-39 minutes 40-59 minutes

1-2 hours $>2$ hours

Evaluation item (for each report item): How do you rate this?

Very poor Poor Acceptable Good Excellent 
8); length of time to the start of definitive clinical assessment ('call back time', standard 9); reported waiting time before receiving treatment when attending a treatment centre (standard 10); and time taken in waiting for a home visit (standard 12). These standards were selected as they could be reported and evaluated by patients based on their own, direct experiences; the other requirements focus more around the processes by which providers must operate (for example, reporting arrangements between providers and commissioning trusts).

The proportion of patients reporting their experiences of out-of-hours care that mapped onto the response target appropriate for that standard are presented. Relationships between reports of care and evaluations of that care were also examined to determine the levels of care required to meet a certain level of patient satisfaction; for example, how quickly do calls have to be answered to ensure that $50 \%$ of patients evaluate the service as 'excellent'.

The contribution of responders' age $(0-4,5-11$, 16-64, $\geq 65$ years), sex (male, female), and socioeconomic status (using the Townsend score quintile derived for each participant's postcode) in predicting their evaluations of service provision was investigated for each of the four national requirement items. A further variable was added accounting for the location (three centres) from which the user received care. To develop the model, users' evaluations in respect of the four items of care were dichotomised ('very poor, poor, or acceptable' versus 'good or excellent'). This categorisation was selected as the cut-point and was broadly similar to that reported elsewhere. ${ }^{11}$ Binary variables categorising reports regarding whether or not the national quality requirements had been met were also analysed. Variables that were significantly associated on univariate analysis with users' evaluations of care $(P<0.05)$ were entered into a binary logistic regression model as potential explanatory variables. Where appropriate, adjusted odds ratios were calculated for variables independently predicting users' evaluations of the service. All analyses were carried out using SPSS (version 15.0).

\section{RESULTS}

Median patient age of the survey population ( $n=$ 1249) was 40 years (interquartile range = 19-64 years; Table 1). Approximately two-thirds (745/1249; 59.6\%) were female. Area three differed from the other two sites with the mean patient age approximately 10 years younger, and higher deprivation scores (indicating greater deprivation) when compared with the other two areas sampled. Five hundred and sixty-four (45.2\%) patients were treated at a treatment centre, 441 (35.3\%) received telephone advice from a health professional, 206 (16.5\%) had home visits, and 38 patients (3.0\%) had their problem dealt with by the call operator.

Following one reminder to non-responders, $627 / 1249$ individuals returned questionnaires $(50.2 \%$ response rate), of whom 570 (45.6\%) provided useable data. Patients providing useable data (Table 2) were older and more affluent than non-responders, although both groups had a similar sex profile. Of 464 individuals who provided information on ethnicity, 452 (97.4\%) reported their ethnic status as white.

Users' reports of service provision suggested that national quality requirements were attained according to around two-thirds of service users for three of the four requirements investigated (Table 3). For the remaining requirement (time spent waiting for an answer to the initial call; standard 8), nearly $87 \%$ of users reported that the national quality standard was attained. While more than $80 \%$ of users who reported that their care had been delivered within the national quality requirement evaluated their care as being of at least a 'good' standard across three of the four criteria examined (and $72.2 \%$ for the other requirement), much smaller proportions of these users evaluated their care as being 'excellent'. Based on these observations, for $50 \%$ of users to evaluate their care as 'excellent' this would require calls to be answered within 30 seconds, call-back within 20 minutes, time waiting for home visits of significantly less than 1 hour, and treatment centre waiting times of less than 20 minutes.

Binary logistic regression models are presented in Table 4. Univariate analysis identified that age,

\section{Table 1. Sociodemographic characteristics of patients surveyed in three study areas.}

\begin{tabular}{|c|c|c|c|c|c|}
\hline \multirow[b]{2}{*}{ Provider } & \multicolumn{2}{|c|}{$\mathrm{Age}^{\mathrm{a}}$} & \multicolumn{2}{|c|}{$\operatorname{Sex}(n, \%)$} & \multirow{2}{*}{$\begin{array}{c}\text { Townsend } 2001 \\
\text { score, median (IQR) }\end{array}$} \\
\hline & Mean (SD) & Median (IQR) & Male & Female & \\
\hline Area One $(n=417)$ & $44.3(27.7)$ & 43 (22 to 68 ) & $169(40.5)$ & $248(59.5)$ & $-0.19(-1.46$ to 1.18$)$ \\
\hline Area Two $(n=416)$ & $45.3(26.8)$ & 44 (21.5 to 70$)$ & $163(39.2)$ & $253(60.8)$ & $-0.48(-1.90$ to 1.38$)$ \\
\hline Area Three $(n=416)$ & $34.3(26.6)$ & 32 (32 to 54$)$ & $172(41.3)$ & $244(58.7)$ & $1.59(-0.51$ to 3.21$)$ \\
\hline All $(n=1249)$ & $41.3(27.5)$ & 40 (19 to 64$)$ & $504(40.4)$ & 745 (59.6) & $0.39(-1.38$ to 1.88$)$ \\
\hline
\end{tabular}

a265/1249 (21.2\%) of the sample were aged $\leq 11$ years, 672 (53.8\%) were aged 16-64 years, and 312 (25.0\%) were aged $\geq 65$ years. $S D=$ standard deviation. $I Q R=$ interquartile range. 
socioeconomic status, and location of care were not associated with participants' evaluations of care. Female sex was associated with adverse evaluations of both the time experienced in waiting for a call-back from a health professional (168/266 females [63.2\%] providing evaluations of 'good' or 'excellent' compared with 131/182 males [72.0\%]), and of the time experienced in waiting for a home visit to take place (27/74 females [36.5\%] providing evaluations of 'good' or 'excellent' compared with $47 / 71$ males [66.2\%]), but not in respect of the length of time encountered in getting through to the service or in the length of time encountered when waiting to be seen following attendance at a treatment centre. For all four standard-related questionnaire items, univariate analysis identified that reports of longer time waiting were associated with adverse evaluations of care. All of the candidate variables were identified as predictors of users' evaluations of the care which they had received.

\section{DISCUSSION}

Four items relating to national requirements for outof-hours service provision were incorporated in this questionnaire. On the basis of the results, services are meeting current standards in their management of the majority of patients. However, achieving 'excellent' levels of user satisfaction (the level to which services and the Department of Health might aspire) would

\begin{tabular}{|c|c|c|c|}
\hline & Responders $^{\mathrm{a}}$ & Non-responders & $P$-value \\
\hline Frequency (\%) & $627(50.2 \%)$ & $622(49.8 \%)$ & $\mathrm{NS}^{\mathrm{b}}$ \\
\hline \multicolumn{4}{|l|}{ Age, years } \\
\hline Mean (SD) & $46.6(27.4)$ & $36.0(26.6)$ & $<0.001^{\circ}$ \\
\hline Median (IQR) & 49 (23 to 70$)$ & $32(11$ to 54$)$ & \\
\hline Sex, female \% & 60.1 & 59.2 & $\mathrm{NS}^{\mathrm{b}}$ \\
\hline $\begin{array}{l}\text { Townsend 2001, } \\
\text { median (IQR) }\end{array}$ & $-0.08(-1.47$ to 1.70$)$ & $0.70(-1.17$ to 1.96$)$ & $0.01^{\mathrm{d}}$ \\
\hline
\end{tabular}

prove extremely exacting for service providers.

Delays encountered in receiving out-of-hours care were consistently identified as independent predictors of adverse evaluations of care. Even if telephone calls were reported as being answered within 30 seconds, only around two-thirds of users reported this as an 'excellent' level of service provision. Where the service response was between 30 and 60 seconds, only around one-fifth of users reported this provision as being 'excellent'. Where a less stringent target of attainment was set (service provision being 'good' or 'excellent'), much higher levels of satisfaction with the experience of out-of-hours care were evident.

Female sex was identified as an independent predictor of adverse evaluations in respect of delays

\begin{tabular}{|c|c|c|c|c|}
\hline & & & \multicolumn{2}{|c|}{ Service provision ${ }^{\mathrm{a}}$} \\
\hline & & & ‘Excellent' & $\begin{array}{l}\text { 'Good' or } \\
\text { 'excellent' }\end{array}$ \\
\hline Item (national quality requirement) ${ }^{\mathrm{b}}$ & Reported service provision & $N(\%)$ & $n(\%)$ & $n(\%)$ \\
\hline $\begin{array}{l}\text { Please estimate how long it took for your } \\
\text { call to be answered }(<60 \text { seconds) }\end{array}$ & $\begin{array}{c}<30 \text { seconds } \\
30-60 \text { seconds } \\
>60 \text { seconds } \\
\text { Total }\end{array}$ & $\begin{array}{c}252(45.1) \\
233(41.7) \\
74(13.2) \\
559(100.0)\end{array}$ & $\begin{array}{c}173(69.2) \\
48(20.6) \\
4(5.4)\end{array}$ & $\begin{array}{c}240(96.0) \\
168(72.1) \\
22(29.7)\end{array}$ \\
\hline $\begin{array}{l}\text { How long did it take for a health professional } \\
\text { to call you back? }(<20 \text { minutes })\end{array}$ & $\begin{array}{c}<20 \text { minutes } \\
20-60 \text { minutes } \\
>1 \text { hour } \\
\text { Total }\end{array}$ & $\begin{array}{c}270(59.9) \\
153(33.9) \\
28(6.2) \\
451(100.0)\end{array}$ & $\begin{array}{c}146(54.7) \\
12(8.0) \\
1(3.7)\end{array}$ & $\begin{array}{c}233(87.3) \\
59(39.3) \\
4(14.8)\end{array}$ \\
\hline $\begin{array}{l}\text { How long did you have to wait before having } \\
\text { treatment at a treatment centre? }(<20 \text { minutes) }\end{array}$ & $\begin{array}{c}<20 \text { minutes } \\
20-39 \text { minutes } \\
40-59 \text { minutes } \\
1-2 \text { hours } \\
>2 \text { hours } \\
\text { Total }\end{array}$ & $\begin{array}{c}213(68.5) \\
61(19.6) \\
24(7.7) \\
10(3.2) \\
3(1.0) \\
311(100.0)\end{array}$ & $\begin{array}{c}113(54.1) \\
7(11.7) \\
0(0.0) \\
0(0.0) \\
1(33.3)\end{array}$ & $\begin{array}{c}176(84.2) \\
14(23.3) \\
3(12.5) \\
0(0.0) \\
1(33.3\end{array}$ \\
\hline $\begin{array}{l}\text { How long did you have to wait for } \\
\text { a home visit? ( }<2 \text { hours) }\end{array}$ & $\begin{array}{c}<1 \text { hour } \\
1-2 \text { hours } \\
>2 \text { hours } \\
\text { Total }\end{array}$ & $\begin{array}{c}91(63.6) \\
29(20.3) \\
23(16.1) \\
143(100.0)\end{array}$ & $\begin{array}{c}31(34.4) \\
1(3.6) \\
1(4.3)\end{array}$ & $\begin{array}{c}65(72.2) \\
4(14.3) \\
5(21.7\end{array}$ \\
\hline
\end{tabular}

${ }^{a}$ Denominator (N) varies slightly between entries on account of missing data. ${ }^{b}$ For some items, the time taken to respond varies depending on the urgency of the call and/or availability of call prioritisation systems based on patient need. To generate dichotomous variables for logistic regression modelling, the cut-points presented here reflect the guidance for individuals with urgent care needs, and assume that no prioritisation systems were available. 


\section{Table 4. Binary logistic regression models describing the contributions of patient characteristics and reported experiences to their evaluations.}

\begin{tabular}{|c|c|c|c|c|}
\hline Evaluation of national quality requirement & Unadjusted OR $(95 \% \mathrm{Cl})$ & $P$-value & Adjusted OR (95\% Cl) & $P$-value \\
\hline \multicolumn{5}{|c|}{ Length of wait for telephone call to be answered $(n=547-563)^{a}$} \\
\hline \multicolumn{5}{|l|}{ Patient age, years (reference group $<5$ years) } \\
\hline $5-11$ & 1.51 (0.51 to 4.46$)$ & 0.44 & - & \\
\hline $16-64$ & 0.77 (0.38 to 1.57$)$ & & & \\
\hline$\geq 65$ & $0.82(0.39$ to 1.73$)$ & & & \\
\hline \multicolumn{5}{|l|}{ Patient sex (reference group = male) } \\
\hline Female & $1.22(0.82$ to 1.82$)$ & 0.33 & - & \\
\hline \multicolumn{5}{|l|}{ Townsend score, quintile (reference group = 1st quintile) } \\
\hline 2nd & $1.70(0.63$ to 4.58$)$ & 0.40 & - & \\
\hline $3 r d$ & $1.11(0.46$ to 2.70$)$ & & & \\
\hline 4th & 0.90 (0.38 to 2.12$)$ & & & \\
\hline 5th & 0.93 (0.38 to 2.30$)$ & & & \\
\hline \multicolumn{5}{|l|}{ Provider (reference group = Area one) } \\
\hline Area two & $0.72(0.45$ to 1.16$)$ & 0.39 & - & \\
\hline Area three & 0.80 (0.49 to 1.32$)$ & & & \\
\hline $\begin{array}{l}\text { Participant reported } \geq 60 \text { seconds until } \\
\text { call answered (reference group }<60 \text { seconds) }\end{array}$ & $0.08(0.04$ to 0.14$)$ & $<0.0001$ & - & \\
\hline \multicolumn{5}{|c|}{ Length of wait for a health professional to call back $(n=436-448)^{a}$} \\
\hline \multicolumn{5}{|l|}{ Patient age, years (reference group $<5$ years) } \\
\hline $5-11$ & $1.46(0.53$ to 4.02$)$ & 0.74 & - & \\
\hline $16-64$ & 1.19 (0.59 to 2.39$)$ & & & \\
\hline$\geq 65$ & 1.42 (0.68 to 2.98$)$ & & & \\
\hline \multicolumn{5}{|l|}{ Patient sex (reference group $=$ male) } \\
\hline Female & $0.67(0.44$ to 1.01$)$ & 0.05 & $0.61(0.40$ to 0.94$)$ & 0.02 \\
\hline \multicolumn{5}{|l|}{ Townsend score, quintile (reference group = 1st quintile) } \\
\hline 2nd & $1.58(0.62$ to 4.03$)$ & 0.77 & - & \\
\hline 3rd & $1.44(0.61$ to 3.40$)$ & & & \\
\hline 4th & $1.25(0.54$ to 2.89$)$ & & & \\
\hline 5th & $1.11(0.46$ to 2.63$)$ & & & \\
\hline \multicolumn{5}{|l|}{ Provider (reference group = Area one) } \\
\hline Area two & $0.96(0.60$ to 1.56$)$ & 0.94 & - & \\
\hline Area three & 0.91 (0.55 to 1.52$)$ & & & \\
\hline $\begin{array}{l}\text { Participant reported } \geq 20 \text { minutes for health professional to } \\
\text { call back (reference group }<20 \text { minutes) }\end{array}$ & $0.29(0.17$ to 0.50$)$ & $<0.0001$ & $0.27(0.16$ to 0.48$)$ & $<0.0001$ \\
\hline \multicolumn{5}{|l|}{ Length of wait for a home visit $(n=140-145)^{a}$} \\
\hline \multicolumn{5}{|l|}{ Patient age, years (reference group $<5$ years) ${ }^{b}$} \\
\hline $16-64$ & $0.78(0.16$ to 3.82$)$ & 0.94 & - & \\
\hline$\geq 65$ & $0.75(0.16$ to 3.56$)$ & & & \\
\hline \multicolumn{5}{|l|}{ Patient sex (reference group $=$ male) } \\
\hline Female & $0.29(0.15$ to 0.58$)$ & 0.0003 & $0.27(0.13$ to 0.55$)$ & 0.003 \\
\hline \multicolumn{5}{|l|}{ Townsend score, quintile (reference group = 1st quintile) } \\
\hline $2 n d$ & $1.07(0.25$ to 4.59$)$ & 0.62 & - & \\
\hline $3 r d$ & $0.51(0.14$ to 1.87$)$ & & & \\
\hline 4th & 0.79 (0.21 to 2.91$)$ & & & \\
\hline 5th & 0.89 (0.22 to 3.53$)$ & & & \\
\hline \multicolumn{5}{|l|}{ Provider (reference group = Area one) } \\
\hline Area two & $1.63(0.73$ to 3.63$)$ & 0.37 & - & \\
\hline Area three & 1.63 (0.73 to 3.63$)$ & & & \\
\hline $\begin{array}{l}\text { Participant reported } \geq 2 \text { hours for home visit } \\
\text { (reference group }<2 \text { hours) }\end{array}$ & 0.20 (0.69 to 0.57$)$ & 0.001 & 0.18 (0.06 to 0.55$)$ & 0.001 \\
\hline
\end{tabular}

encountered in two of the four quality requirement domains investigated: the time spent waiting for a health professional to call back and the time spent waiting for a home visit. McKinley and Roberts ${ }^{12}$ have previously noted that female sex was associated with adverse evaluations of out-of-hours care. The potentially complex contribution of sex as a determinant of satisfaction with out-of-hours care 


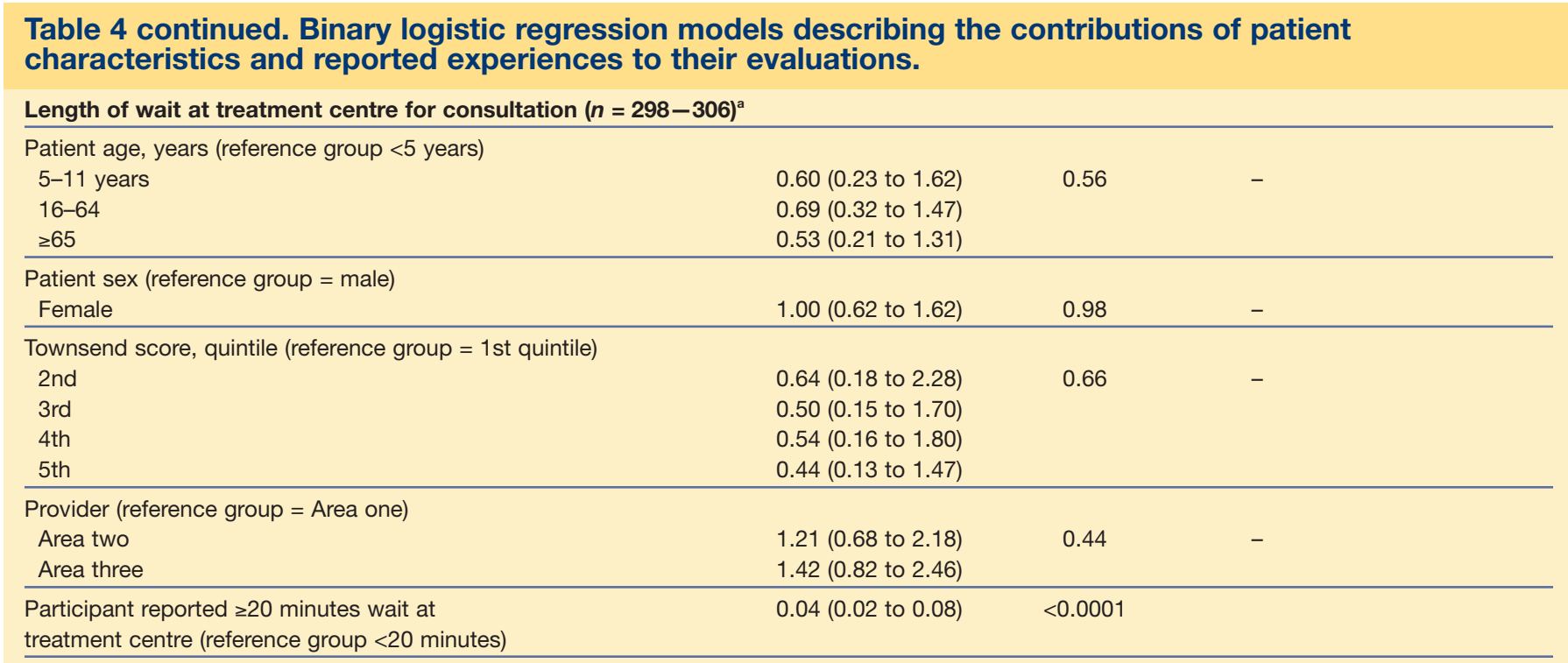

a'Responders' evaluative responses categorised into a binary variable of 'very poor/poor/acceptable' and 'good/excellent'. 'There were insufficient data from patients aged 5 to 11 years to calculate an odds ratio for this category.

(such as the relationship between sex and carer status) is an area that would benefit from further carefully planned and research modelling.

An earlier report derived from this study revealed that age was a predictor of satisfaction with the outof-hours consultation, but was not a predictor of satisfaction with those arrangements established to provide access to the service. ${ }^{4}$ In the current study age was not an independent predictor of adverse evaluations in terms of delays encountered in accessing the out-of-hours service. While many studies have identified that older individuals tend to express greater satisfaction with health care than younger individuals, the current results suggest that they are equally reluctant to accept delays in service provision.

\section{Strengths and limitations of the study}

This study was based on a large sample size, using participants drawn from three geographically distinct areas of the UK. Following only one reminder, although the survey response rates were somewhat low, responses rates were in line with those reported by recent community-based surveys from the $\mathrm{UK}^{13-15}$ and elsewhere. ${ }^{16,17}$ While low response rates can introduce bias, ${ }^{6,18}$ it is not possible to predict the magnitude or direction of the effect with any certainty, as the limited previous research is contradictory. For example, there is some evidence that response bias suggests an under-reporting by individuals who had less satisfactory experiences, ${ }^{6}$ although this is counter-balanced by findings that postal surveys (such as adopted in this study) tend to give more variable responses, as people who feel strongly either way are more likely to respond.
Despite sampling in an area of high ethnic minority representation, individuals from ethnic minorities were underrepresented in the responder sample compared to UK normative data, ${ }^{19}$ and older, more affluent responders were overrepresented. The sampling also excluded some service users on ethical grounds, such as individuals with end-stage terminal illness or children aged 12 to 16 years, limiting the generalisability to these groups.

The research is based on patients' reports of outof-hours service provision, combined with subsequent evaluations of the adequacy of the recollected experiences. The validity of these reports was not investigated in detail by, for example, cross checking patient reported waiting times with process data recorded in healthcare provider computer systems. Other studies from different service settings have raised questions regarding the validity of patient reports of healthcare utilisation,,$^{20}$ noting a tendency for inaccuracy of recall ${ }^{21}$ and under-reporting of service use, especially among older service users ${ }^{22,23}$ and over longer periods of recall-time such as 6 or 12 months. ${ }^{22,24}$ The current research was based on questionnaire surveys completed within 2 weeks ${ }^{4}$ of a contact with the out-of-hours services, and thus may be subject to less recall-bias than studies which are dependant on longer periods of recall.

National quality requirements ${ }^{1}$ for the delivery of out-of-hours services set explicit standards for service provision across 13 domains. Patients' reports and evaluations of care were examined for only four of these domains, selecting only those areas which could feasibly be included within a questionnaire relating to the direct experiences of service users. Furthermore, the national requirements 
make clear that service provision may be matched to patients' needs in those services operating a system for prioritising patient contacts following an initial assessment of their clinical need. Since the aim of the study was to gain an overview of patients' experiences of service delivery rather than to focus on individual patient care, the classification of the urgency of calls undertaken by call handlers in their preliminary assessments of patients' needs was not taken into account.

This study demonstrates the value of combining patients' reports of care with questions inviting their evaluation of out-of-hours care. This process offers potential in informing standard setting and service configuration..$^{24,25}$

It is clear that UK out-of-hours service users have high expectations in respect of their quality of care. While users' reports and evaluations are predicated on their experience of care, patient preferences for care have been proposed to be independent of experience. ${ }^{6}$ Although patient preferences have been considered in the arena of clinical research, ${ }^{26,27}$ it is suggested that patients' expectations represent a distinct further area for consideration in a model of patients' views of health services. Furthermore, it is speculated that satisfying user preferences for care may be more difficult than meeting their expectations of care, as the latter is moderated by both personal experience and the wider social and political context in which care is delivered. Recognition of the role of user expectations as a mediator of patient reports of satisfaction has been previously reported. ${ }^{28}$ While there is reasonable consensus that such expectations play an important role in understanding users' judgements of service quality and satisfaction, ${ }^{18}$ there remains considerable theoretical uncertainty within psychology as to how cognitive and affective processes combine when making such evaluations.

In this study, service users whose care did not meet publicised targets of service provision reflected this in adverse satisfaction ratings. A previous study of out-of-hours care ${ }^{29}$ has reported that meeting patients' expectations of care is a major independent predictor of patients' satisfaction with care. Satisfaction with care may reflect the size of the gap between patients' expectations and their experience of care with a smaller gap being associated with improved satisfaction. This simple but important hypothesis requires testing with prospectively collected data in studies designed to address the research question. If correct, the hypothesis suggests that improved reports of satisfaction with care may be achieved by improving patients' experience of care, but also by setting and communicating realistic targets in respect of healthcare delivery with a view to informing patients' expectations of health service delivery.

\section{Funding body}

UK Department of Health

Ethical approval

North and East Devon NHS Research Ethics Committee $(126 / 12 / 2004)$

\section{Competing interests}

Michael Greco is a director of Client Focused Evaluation Programme (UK). All other authors have stated that there are none.

\section{Acknowledgements}

We are grateful for the support of out-of-hours service providers and service users who contributed to this study.

\section{Discuss this article}

Contribute and read comments about this article on the Discussion Forum: http://www.rcgp.org.uk/bjgp-discuss

\section{REFERENCES}

1. Department of Health. National quality requirements in the delivery of out-of-hours services. London: Department of Health, 2005.

2. Department of Health. Raising standards for patients, new partnerships in out-of-hours care: an independent review of GP out-of-hours services in England (The Carson Report). London: Department of Health, 2000.

3. Department of Health. National standards for better health. London: Department of Health, 2004.

4. Campbell JL, Dickens A, Richards SH, et al. Capturing users' experience of UK out-of-hours primary medical care: piloting and psychometric properties of the out-of-hours patient questionnaire. Qual Saf Health Care 2007; 16(6): 462-468.

5. Department of Health. Direction of travel for urgent care: a discussion document. London: Department of Health, 2008.

6. Wensing M, Elwyn G. Methods for incorporating patients' views in health care. BMJ 2003; 326(7394): 877-879.

7. Richards SH, Pound P, Dickens A, et al. Exploring users' experiences of accessing out-of-hours primary medical care services. Qual Saf Health Care 2007; 16(6): 469-477.

8. Streiner DL, Norman GR. Health measurement scales: a practical guide to their development and use. Oxford: OUP, 2003.

9. Edwards P, Roberts I, Clarke M, et al. Increasing response rates to postal questionnaires: systematic review. BMJ 2002; 324(7347): 1183.

10. McColl E, Jacoby A, Thomas L, et al. Design and use of questionnaires: a review of best practice applicable to surveys of health service staff and patients. Health Technol Assess 2001; 5(31): $1-256$.

11. National Audit Office. The provision of out-of-hours care in England. Comptroller and Auditor General. London: The Stationery Office, 2006.

12. McKinley RK, Roberts C. Patient satisfaction with out of hours primary medical care. Qual Saf Health Care 2001; 10(1): 23-28.

13. Salisbury C, Burgess A, Lattimer V, et al. Developing a standard short questionnaire for the assessment of patient satisfaction with out-ofhours primary care. Fam Pract 2005; 22(5): 560-569.

14. Ipsos MORI. GP patient surveys: your doctor, your experience, your say. London: Ipsos MORI 2007.

15. Department of Health. National survey of local health services 2006: summary report of key findings from the study. London: Picker, 2006.

16. Moll van Charante E, Giesen P, Mokkink H, et al. Patient satisfaction with large-scale out-of-hours primary health care in The Netherlands: development of a postal questionnaire. Fam Pract 2006; 23(4): 437-443.

17. Van Uden CJ, Ament AJ, Hobma SO, et al. Patient satisfaction with out-of-hours primary care in the Netherlands. BMC Health Serv Res 2005; 5(1): 6 .

18. Crow $\mathrm{R}, \mathrm{Gage} \mathrm{H}, \mathrm{Hampson} \mathrm{S}$, et al. The measurement of satisfaction with healthcare: implications for practice from a systematic review of the literature. Health Technol Assess 2002; 6(32): 1-244.

19. National Statistics UK. Ethnicity and identity. http://www.statistics.gov.uk/cci/nugget.asp?id=455 (accessed $28 \mathrm{Nov}$ 2008).

20. Bhandari A, Wagner T. Self-reported utilization of health care services: Improving measurement and accuracy. Med Care Res Rev 2006; 63(2): 
$217-235$.

21. Ritter PL, Stewart AL, Kaymaz H, et al. Self-reports of health care utilization compared to provider records. J Clin Epidemiol 2001; 54(20): 136-141.

22. Richards SH, Coast J, Peters TJ. Patient-reported use of health service resources compared with information from health providers. Health Soc Care Community 2003; 11(6): 510-608.

23. Jordan K, Jinks C, Croft P. Health care utilization: measurement using primary care records and patient recall both showed bias. J Clin Epidemiol 2006; 59(8): 791-797.

24. Bower P, Roland M, Campbell JL, Mead N. Setting standards based on patients' views on access and continuity: secondary analysis of data from the general practice assessment survey. BMJ 2003; 326(7383): 258.

25. Salisbury C, Goodall S, Montgomery AA, et al. Does advanced access improve access to primary health cam? Questionnaire survey of patients. Br J Gen Pract 2007; 57(541): 615-21.

26. Bower $\mathrm{P}$, King $\mathrm{M}$, Nazareth I, et al. Patient preferences in randomised controlled trials: conceptual framework and implications for research Soc Sci Med 2005; 61(3): 685-95.

27. Dalal HM, Evans PH, Campbell JL, et al. Home-based versus hospitalbased rehabilitation after myocardial infarction: a randomized trial with preference arms — Cornwall Heart Attack Rehabilitation Management Study (CHARMS). Int J Cardiol 2007; 119(2): 202-211.

28. Linder-Pelz SU. Toward a theory of patient satisfaction. Soc Sci Med 1982; 165(5): 577-582.

29. McKinley RK, Stevenson K, Adams S, Manku-Scott TK. Meeting patient expectations of care: the major determinant of satisfaction with out-of-hours primary medical care? Fam Pract 2002; 19(4): $333-338$. 